\title{
Digital Platforms in the Global South: Foundations and Research Agenda
}

\author{
Kari Koskinen $^{1}$, Carla Bonina ${ }^{2(\bowtie)}$, and Ben Eaton ${ }^{2}$ \\ ${ }^{1}$ Department of Management, London School of Economics and Political \\ Science, Houghton Street, London, UK \\ k.m.koskinen@lse.ac.uk \\ 2 Surrey Business School, University of Surrey, Guildford, UK \\ \{c.bonina, b. eaton\}@surrey.ac.uk
}

\begin{abstract}
Digital platforms have become integral to many of the everyday activities that people across the globe encounter in areas like transportation, commerce and social interactions. Research on the topic has largely concentrated on the general functioning of these platforms in terms of platform governance, business strategies and consumer behaviour. Despite their significant presence in the global South, the developmental implications of digital platforms remain largely understudied. In part, this is because digital platforms are a challenging research object due to their lack of conceptual definition, their spread across different regions and industries, and their intertwined nature with institutions, actors and digital technologies. The aim of this paper is therefore twofold: to provide a conceptual definition of digital platforms, and to identify research strands in international development contexts. To do so, we draw from digital platforms literature, differentiate between transaction and innovation platforms and expose their main characteristics. We the present four strands in the form of research questions, illustrated with concrete examples, that can assist to pursue relevant studies on digital platforms and international development in the future.
\end{abstract}

Keywords: Digital platforms $\cdot$ Development $\cdot$ Global South · Research agenda $\cdot$ Information systems

\section{Introduction}

Digital platforms hold a central position in the business plans of some of the biggest companies of today, such as Facebook, Google, Alibaba and Apple. A survey conducted in 2015 identified 176 platform companies in the world, with an estimated global market capitalisation of 4.3tn USD - larger than Germany's gross domestic product [16]. The same study revealed that publicly traded platforms alone gave direct

We gratefully acknowledge funding from the UK ESRC Development Implications of Digital Economies (DIODE) research network to conduct part of this work. We also benefited from useful comments from Richard Heeks, the members of the DIODE network and the participants at the Development Studies Association Conference at the University of Manchester in June 2018. 
employment to around 1.3 million people. Even though many of these platforms have their origins in the global North, they are becoming important also to the people in the global South due to increased access to devices and connectivity in these regions. Overall, digital platforms occupy more significant roles in areas like employment opportunities, social networking and innovation activities, which are all moving online in growing quantities. In addition, more companies in the global South have built digital platforms of their own, which at first targeted local markets but have also expanded to other areas of the globe [7, 17].

No doubt that, given these figures, digital platforms have the potential to generate social and economic value in the global South, yet their developmental impacts are not entirely understood. Practitioners and scholars acknowledge their significance for the societies in the global South [7, 28, 32, 35], but it is less obvious how digital platforms should be studied from a developmental perspective. Part of the problem is the lack of clarity regarding the understanding of what a digital platform is and how they should be conseptualised. In addition, digital platforms are a challenging research object as they spread across different regions, disrupt industries, and are intertwined with surrounding institutions, markets and digital technologies [9].

This paper seeks firstly to contribute to the studies of digital innovation and international development [32] by providing a conceptual definition of digital platforms to scope their study. Second, we argue that digital platforms are likely to have both positive and negative impacts to the people and societies in the global South. The paper therefore suggests four research strands, potential theoretical angles and methods to provide digital economy and international development scholars a starting point for analysis and understanding of the developmental role of digital platforms in their respective contexts.

\section{Defining Digital Platforms}

Overall, most digital platforms can be seen as sharing three basic characteristics: they are technologically mediated, enable interaction between user groups, and allow those user groups to do particular things $[6,9,16,27]$. Traditionally the definition of digital platforms has also depended on the field under which they have been studied. Within economics, the discussion has evolved more around the demand and supply functions within these platforms and how they differ from other types of market settings [15]. In studies concentrating on their technological components, the focus has been on their technological and digital characteristics such as layered architecture and modularity [40]. More generally, attention has been given for example to the socio-technical dimensions of digital platforms such as their impact on organisational structures or international standards [9]. Digital platforms themselves differ on characteristics such as market capitalisation, sector or industry they are situated in, governance model, country of origin and geographical reach [17], all of which might alter the ways a particular platform operates and the target segments it sets to cater.

Irrespective of this, for any type of research on digital platforms it is important to understand what type of platforms one is studying. Gawer [20] and Evans and Gawer [16] classify platforms according to their principal purpose and identify roughly three different types of digital platforms: transaction platforms, innovation platforms and integration platforms. 


\subsection{Types of Platforms: Transaction, Innovation and Integration}

Transaction Platforms. Much research on digital platforms has concentrated around transaction platforms, which are sometimes referred to as multi-sided markets or exchange platforms. Their main purpose is to facilitate transactions between different organisations, entities and individuals, such as connecting buyers with sellers, drivers with passengers, composers with music companies, and so on. Transaction platforms can be especially useful in reducing transaction costs by allowing different agents to find each other more easily, and to overall reduce some of the frictions in the transaction process [16].

Transaction platforms make it possible to exchange digital services and can be divided according to their principal purpose. Common transaction digital platforms are found in social media (e.g. Facebook), e-commerce (Mercado Libre), the 'gig' economy platforms (Upwork), or those built around the notion of the sharing economy (Airbnb). These platforms are often studied from the viewpoint of economics as their management is related to areas like pricing and contractual factors. The core value created relies on the presence of network effects, whether direct or indirect. Direct network effects, in simple terms, refer to the fact that a network (or platform) becomes more valuable to each member as more users join [20]. Examples of these would MPesa and WhatsApp, since every new member joining creates value for the others as there are more users to interact with. Indirect network effects are to some extent similar to direct ones but refer instead to the value created as a result of increasing number of users in groups that are complementary to each other. That is, the decision to join a platform from the point of view of a member belonging to a given user group (e.g. sellers) depends on the amount of users in a given complementary group (e.g. buyers) [24]. Depending on the principle purpose of the platform, users are attracted to the platform by the number of available cleaners in the case of Domestly, work opportunities (Upwork), and drivers (Uber), and the same applies the other way around for people or companies looking to hire cleaners, provide employment or look for passengers.

Although network effects are among the most important features of transaction platforms, they provide a rather stable view of digital platforms and may easily miss other important research areas such as how platforms evolve over time. In addition, the focus on network effects often simplifies platform users to mere consumers and tends to view transactions generally as buyer-seller situations, where in reality, the relationships between platform users can be more varied [13, 14].

Innovation Platforms. Innovation platforms are formed of technological building blocks that provide a basis for developing services and products. A typical example of an innovation platform is mobile operating system Android, which enables third party developers to build applications on top of the operating system [16]. Innovation platforms provide third party developers their own set of tools and resources that developers then combine and use in ways to enable new applications for commercial or other type of use.

Some of the notions put forward by the economic perspective do not quite fit innovation platforms; the economic perspective, it is argued, does not take into account 
design related factors and their implications to incentivise innovation [20]. As a result, studies on innovation platforms have often adopted an engineering, information systems or product management perspective. Their emphasis has often been on the technological architectures that enable innovation, in addition to the design and production aspects of these platforms as well as on the role of interfaces in the interaction between the platform and the third party complementors [2, 12, 37, 39].

The focus on digital innovation platforms is to understand how the relationship between the core (platform) and the periphery (the third party developers or complementors) is structured, what kinds of resources are being provided for the complementors, and what the usage of those resources implies [2]. In addition to enabling creation of innovations, innovation platforms also pose constraints for the complementors. For a platform owner, the issue is one of balancing between these two, as the platform owner needs to provide the complementors the necessary resources for them to build services on top, while at the same time controlling the platform and keeping it as stable as possible [22]. The relation between the core and the developers may also differ from one country to another for instance in terms of monetisation [5].

Integration Platforms. Integration platforms combine aspects of the two principal platform types - that is, transaction and innovation platforms [16]. It could be argued that any digital transaction platform requires an innovation platform beneath it, since as the name implies, transaction platforms are always built on a particular platform such as Android, Linux, Windows or something else. The key points of transaction and innovation platforms also apply to integration platforms, and therefore are not discussed in this study.

Table 1. Key characteristics of innovation and transaction platforms.

\begin{tabular}{l|l|l}
\hline $\begin{array}{l}\text { Type of digital } \\
\text { platform }\end{array}$ & Transaction & Innovation \\
\hline Purpose & $\begin{array}{l}\text { Matches users or user groups, the } \\
\text { value for a user increases with the } \\
\text { number of users in a user group }\end{array}$ & $\begin{array}{l}\text { An extensible codebase as a core } \\
\text { that enables the adding of third- } \\
\text { party modules that complement } \\
\text { the core }\end{array}$ \\
\hline $\begin{array}{l}\text { Key target } \\
\text { groups }\end{array}$ & Participants to a transaction & Application developers \\
\hline $\begin{array}{l}\text { Key } \\
\text { governance } \\
\text { issues }\end{array}$ & $\begin{array}{l}\text { Attracting users from the relevant } \\
\text { groups (indirect/direct) }\end{array}$ & $\begin{array}{l}\text { Relationship between developers } \\
\text { and platform owners }\end{array}$ \\
\hline Theories & $\begin{array}{l}\text { Multi-sided markets, indirect and } \\
\text { direct network effects }\end{array}$ & $\begin{array}{l}\text { Boundary resources, platform } \\
\text { openness, platform ecosystem }\end{array}$ \\
\hline $\begin{array}{l}\text { Developmental } \\
\text { questions }\end{array}$ & $\begin{array}{l}\text { Income/job opportunities, filling } \\
\text { institutional voids, removal of } \\
\text { market frictions }\end{array}$ & $\begin{array}{l}\text { Creation of app economies, } \\
\text { development of tools (apps) to } \\
\text { solve local challenges }\end{array}$ \\
\hline Examples & $\begin{array}{l}\text { MPesa, Whatsapp, Skype. Airbnb, } \\
\text { Mercado Libre, Uber }\end{array}$ & \begin{tabular}{l} 
Apple iOS, Linux, Android, SAP \\
\hline
\end{tabular} \\
\hline
\end{tabular}


Table 1 lists the key characteristics of the two types of digital platforms. Currently, a vast majority of digital platforms with the potential to generate societal impacts in developing countries are transaction platforms. However, as noted above, these transaction platforms have a technological basis that in some cases also offers tools to create complementary services and therefore holding characteristics of an innovation platform. A typical example would be Facebook, and its division Facebook for Developers. Therefore, we argue it is important to be aware of the key factors that underlie the functioning of innovation platforms as well. Furthermore, as the technologies needed for the creation of applications are reaching people in developing countries at an increasing pace, the importance of innovation platforms, and with that their societal impact, is likely to increase.

No matter the type of digital platform, in a research regarding platforms it is important to unfold how digital platforms are connected to other socio-technical dimensions, such as actors, institutions and entities. In this sense researchers need to be aware of platforms being part of ecosystems, which are crucial for making the platform function and ultimately to become successful.

\subsection{Digital Platforms and Their Ecosystems}

Innovation and transaction platforms are rarely isolated. As a result, mere definitions provide a basis for studying digital platforms but stop short in describing how platforms may or may not help in contributing to developmental factors, such as inclusion or equality in access. The latter requires taking a context-sensitive approach that extends beyond their mere technological constructs and organisational effects. De Reuver and colleagues [9] echo this claim and point out that "the platform debate should also seek to address the broader issue of how digital platform innovation directly relates to issues of societal and global interest” (p. 132).

Both innovation and transaction platforms tend to be linked to other platforms, organisations, regulators and other different types of entities and actors, and have implications to all of those in addition to their users. Together these form entire ecosystems, in which different parts of the ecosystem are in constant interaction and overall can capture a multitude of social, political and technological factors, agents and attributes. An example of a digital innovation platform ecosystem can be seen in the socalled "app economies", with actors at its core creating and maintaining a platform and an app marketplace, plus small and large companies that produce apps that platform" [30]. As a consequence, an app economy offers a good example of both technological as well as business-driven aspects and their largely social dimensions built into them. More importantly, the notion of ecosystem questions where to draw digital platform boundaries. In part, this is why research on digital platforms is a complex undertaking. One has to be able to carve out the key actors and dimensions of the platform under study, whether they are included directly, or nevertheless affected by the phenomena under study. 


\section{Research Priorities on Digital Platforms and Development}

Given their growing importance in the Global South, we build in this section what we think may be four important areas for future work on the subject. As a general rule, digital platforms are seen particularly useful in removing market frictions [15], which exist in abundance in many developing countries for example due to insufficient information, weak institutions and poor infrastructure [11]. As a result, digital platforms hold promise especially in the context of global South in solving different societal and developmental challenges. The impacts of digital platforms may come in various forms, some of which may be positive and others negative [10], and may work only to amplify existing developing conditions [38]. For example, as certain parts of transactions are hidden in a give digital platform, On a more macro level, there is also a danger of unfair distribution of resources and work between the global South and North, resonating with the arguments made by dependency theorists such as Frank [18].

Below we provide four research areas in the form of questions that we consider relevant for future research on the domain. We believe that each would enable us in different ways to have a better understanding of digital platforms operating in the global South.

\subsection{How to Release the Developmental Potential of Innovation Platforms?}

One of the key characteristics of innovation platforms is to act as the foundation upon which other firms can build complementary products, services or technologies [21]. A relevant case to study the developmental potential of innovation platforms is presented in the realm of open government data - data released by governments in digital format, publicly available for anyone to use. New digital social innovation ventures based on open data promise to contribute to global development goals, such as economic growth, job creation, social and economic inclusion and access to public services such as healthcare. Whilst open government data implementations may have been referred to as platforms, there has been little research from a platform perspective. This is curious when, actually, a lot of what is happening in the field of open data is about growing and nurturing an ecosystem of third party innovators, which can capitalise on the datasets of an open data platform to provide services to citizens or the government itself. In this context, Bonina and Eaton [3] draw on boundary resource theory to study how to cultivate a vibrant ecosystem of open data innovators in Latin America. Using empirical data the authors compare and analyse three open government data initiatives in the cities of Buenos Aires, Mexico City and Montevideo to identify how platform innovation governance evolves over time. The outcome of the analysis proposes a theoretical model which describes a set of tools and rules open data platform authorities can use to stimulate, support and grow both data suppliers and data re-users with an innovation focus. This is an example on how theoretical strands from innovation platforms could be applicable to an international development context.

Another angle to study innovation platforms in the global South is to look at the particular affordances they offer. Affordances have been defined in slightly different ways, but in principle affordances are the acts and functions an artefact affords to its 
users [19, 23, 33]. In relation to digital platforms, affordances provide a tool to analyse the impacts digital platforms have in terms of development. In general, the affordance lens places emphasis on how platforms are designed and developed; it asks questions such as what it allows its users to do and similarly, what kinds of actions it prevents. Usage of affordances in the study of platforms and development can be illustrated through the example of the Ugandan marketplace application Kudu [34]. Kudu enables farmers selling their harvest to connect with buyers and it uses simple SMSs to function. Despite this, the backend technology of Kudu is quite developed as it relies on specifically designed matching algorithms that connect the buyers and sellers (i.e. the matching is done by the application itself instead of the buyers and sellers themselves). What Kudu affords to the sellers is better access to the buyers while also providing certain protection for them of having a fair price. Similarly, it enables the buyers to connect with sellers that might otherwise be hard to reach. As a whole, the affordances Kudu provides enable the removal of market frictions and while doing so replacement of old or even creation of new institutional settings [1, 36].

\subsection{How Do Digital Platforms in the Global South Differ from the Ones in the Global North and What Are Their Institutional Implications?}

Due to the socio-technical nature of digital platforms, the surrounding contextual factors are likely to impact the ways digital platforms are designed and the way they operate in different locations. The global South often faces challenges in areas like weaker infrastructure, institutions and also the local customs that vary when moving from one culture or society to another. As a result, digital platforms operating in the global South require certain adaptations or can be quite different in relation to their purpose, design or operation. One example of this can be seen in Facebook's drive to make its platform more usable in low bandwidth areas [4, 26], but also the types of platforms that are being developed often differ considerably from those that are being targeted for users in the global North as can be seen in the above mentioned agricultural market place application Kudu [34].

Seen through institutions, digital platforms can be challenging the prevailing institutional logics and replacing them; alternatively, they may set the basis for creating institutions in societal areas where there have not necessarily been any, which is claimed to often happen in a developing country context and referred to as institutional voids [29]. In the process of replacing existing institutions digital platforms may deinstitutionalise current norms and practices and put in place their own. The users of digital platforms become therefore exposed to new ways of performing particular practices, and if those are accepted by users, the institutional characteristics offered by the platforms become the new norm and get institutionalised into the surrounding society. Especially in relation to weak institutions and institutional voids, digital platforms and the affordances they hold can form a basis for building institutions. Institutions often display themselves through relevant agents, making agent-focused research relevant also under this particular research area.

The institutionalisation of new norms and forms of practices can have both negative and positive impacts for developing countries as a whole. In order to better understand it, it is important to study how digital platforms in the global South differ from the ones 
in the global North by mapping the key differences between them. From there one can adopt the institutional lens and investigate the impacts of the institutional settings that digital platforms are putting in place. This will enable researchers to also assess whether platforms originating in the global South are better positioned to take into account the contextual and institutional factors in their targeted locations and as a result, provide more positive developmental impacts to local communities and agents.

An example of the work on digital platforms and institutions can be seen in Go-Jek, which is an Indonesian ride-hailing app that started off by providing motorcycle taxi services in the form of passenger rides as well as food and package delivery. It has then expanded to other business areas, for example by launching its own payment system. What made Go-Jek particularly successful in comparison to the alike Uber was its usage of motorcycle taxis In places like Jakarta that suffer from traffic congestion, motorcycles are a much faster method of transportation than cars. Go-Jek also provides employment to the motorcycle taxi drivers, and although many of them were motorcycle taxi drivers already before, they see that they have more work now and spend less time idle, seeing their incomes increasing. Go-Jek also gave loans to drivers so that they could buy a smartphone and provided assistance for drivers who lacked paperwork to register as a legal Go-Jek driver. By growing fast and employing hundreds of thousands of drivers and serving millions of users Go-Jek also had the political capital that helped it when a ban on ride-hailing transport apps was declared; leading to the ban being overturned only $12 \mathrm{~h}$ later. Overall, Go-Jek has to some extent institutionalised the ways motorcycle taxi services are used via an app, changing the existing landscape. At the same time, worries exist of the type of work that Go-Jek and other similar services provide, often providing little working protection if any [8, 31].

\subsection{Do Transaction Platforms Exacerbate Inequalities?}

The majority of biggest digital platforms operating in the global South are transaction platforms, which have the capability of shaping local institutional settings in various ways, both positive and negative. From a developmental perspective, the question that follows is whether the positives outweigh the negatives, and if not what can be done to rectify the situation. One clear research area on the developmental impacts of these transaction platforms is the issue of whether those actually diminish or exacerbate inequalities between different users and agents, be those connected to the platform or otherwise indirectly affected by the platform's existence.

For example, Heeks [25] has noted that online labour platforms have had positive impacts in developing countries in terms of employment opportunities, inclusion, objectivity, reasonable earnings, career development, flexibility and in reducing travel as well as environmental costs. Regarding opportunities and inclusion, platforms enable transfer of employment opportunities from global North to global South and at the same time help to remove some of the institutional barriers that may inhibit certain groups such as women from accessing work opportunities. Similarly, online labour platforms tend to be more objective as traditional cues like disability, accent or age are not necessarily present in an online environment. On average, online labour also pays better than many traditional jobs, allows workers to update their skills and progress in their careers, and enables flexibility regarding time and location. The latter also cuts 
down travel, and with that, environmental costs. At the same time, online labour may also have negative impacts such as low levels of stability, limited or often non-existent social protection. Sometimes the type of work that labour platforms offer is repetitive and even to some extent harmful. In a similar manner, even some of the positive impacts are debatable as the flexibility in working hours may in some cases mean working late at night. Career development is neither guaranteed and can also be practically non-existent.

As this example shows, it is entirely possible for a platform to have both negative and positive impacts. In some cases the impact from a particular area like career development is likely to depend on the research perspective, for example is the issue studied from the perspective of the person doing the job or the overall situation that prevailed before the online platform in question was created.

In terms of inequalities, the key questions that are to be answered revolve around factors that are needed to participate in the platform and with that, who or which agents are able to do so. If understood from the perspective of frictions, transaction platforms are seen capable of removing many of those, but at the same time it is also necessary to understand if they actually also put some other frictions in place. Furthermore, not all frictions are automatically bad, and the removal of some of those may also entail negative consequences for particular agents or user groups. Finally, it is vital to have a holistic view on what are the reasons that make certain agents excluded from using the platform and others included.

\subsection{What Are the Digital Platform Alternatives?}

All of the biggest transaction platforms and many of the innovation platforms are governed by private companies. However, digital platforms also offer public institutions and co-operatives a tool to drive their objectives. In such cases the main objective for the platforms is not necessarily profit-making. That may have a role in terms of the purposes of the platforms and also in the way the platforms have been designed, but it may not be the dominant logic. As a result, important research areas on the developmental impacts of digital platforms may inquire into what alternatives exist to the privately run digital platforms, and what kinds of implications that may have in terms of the platforms' impacts. Furthermore, digital platforms that have alternative governance models may not necessarily have to be strictly public, private or community-owned, but can also take the form of hybrids where several ownership types are present.

These platforms can also take a slightly different approach in terms of their offerings. Already many governmental institutions via the form of open data, but also some private ones (e.g. Uber Movement) are providing data for third party developers that can then be used for research purposes but also for building applications on top of these data sources. These kinds of data platforms fall under the innovation platform category, yet their objectives and overall functioning might differ quite a bit from the likes of Apple's iOS or Android. By being possibly primarily motivated by reasons other than profit and having more social goals built into them, these types of alternative digital platforms may also be more capable of delivering developmental results. Whether this actually occurs or not and what is their general impact, is a matter that requires further research. 


\section{Conclusion}

In this work, we set out to provide a typology of digital platforms that could help to bring more clarity and to equip researchers to investigate the developmental implications of digital platforms. We outline four particular research strands that share the objective of uncovering the effects and developmental implications that digital platforms may have in developing country contexts. Of course, the strands we propose are by no means exhaustive. We suggest that understanding the developmental impact of digital platforms will benefit from an interdisciplinary view on the matter. We hope this foundational work can inspire both scholars and practitioners to move our understanding of both the benefits and costs that digital platforms can offer for international development. We hope a broader engagement with this increasingly important phenomenon can guide future interventions, including the need for regulation, the provision of fairer rules or the generation of new institutions in the world of digital platforms.

\section{References}

1. Avgerou, C.: Information Systems and Global Diversity. Oxford University Press, Oxford, New York (2002)

2. Baldwin, C.Y., Woodard, C.J.: The architecture of platforms: a unified view. In: Gawer, A. (ed.) Platforms, Markets and Innovation. Edward Elgar, Cheltenham (2009)

3. Bonina, C., Eaton, B.: The governance of third party innovation in open government data platforms: evidence from Buenos Aires, Mexico City and Montevideo. In: Academy of Management Global Proceedings, vol. Surrey (2018)

4. Cabral, B.K., Kandrot, E.: The Technology Behind Preview Photos (2015). https://code.fb. com/uncategorized/the-technology-behind-preview-photos/. Accessed 29 June 2018

5. Caribou Digital: Winners and Losers in the Global App Economy. Caribou Digital Publishing, Farnham, Surrey, United Kingdom (2016). http://cariboudigital.net/winners-andlosers-in-the-global-app-economy/

6. Constantinides, P., Henfridsson, O., Parker, G.G.: Introduction-platforms and infrastructures in the digital age. Inf. Syst. Res. 29(2), 381-400 (2018)

7. David-West, O., Evans, P.: The Rise of African Platforms: A Regional Survey (The Emerging Platform Economy Series No. 2) (2015)

8. Davis, J.: Digital Lessons from Go-Jek, Indonesia's Answer to Uber and Grab (2018). https:// knowledge.insead.edu/entrepreneurship/digital-lessons-from-go-jek-indonesias-answer-touber-and-grab-8871. Accessed 30 June 2018

9. de Reuver, M., Sørensen, C., Basole, R.C.: The digital platform: a research agenda. J. Inf. Technol. 33(2), 124-135 (2018)

10. Donner, J.: A Vision of Digital Development in 2028 (2018). https://medium.com/cariboudigital/a-vision-of-digital-development-in-2028-43c8ff3c69e. Accessed 13 May 2018

11. Drouillard, M.: Addressing voids: how digital start-ups in Kenya create market infrastructure. In: Ndemo, B., Weiss, T. (eds.) Digital Kenya. Palgrave Macmillan, London (2017). https://doi.org/10.1057/978-1-137-57878-5_4

12. Eaton, B., Elaluf-Calderwood, S., Sørensen, C., Yoo, Y.: Distributed tuning of boundary resources: the case of Apple's iOS service system. MIS Q. 39(1), 217-243 (2015) 
13. Eisenmann, T., Parker, G., Alstyne, M.V.: Opening Platforms: How, When and Why? (SSRN Scholarly Paper No. ID 1264012). Social Science Research Network, Rochester, NY (2008)

14. Eisenmann, T., Parker, G., Alstyne, M.V.: Platform envelopment. Strateg. Manag. J. 32(12), 1270-1285 (2011)

15. Evans, D.S., Schmalensee, R.: Matchmakers: The New Economics of Multisided Platforms. Harvard Business Review Press, Boston (2016)

16. Evans, P., Gawer, A.: The Rise of the Platform Enterprise: A Global Survey (The Emerging Platform Economy Series No. 1). The Center for Global Enterprise (2016)

17. Evans, P.: The Rise of Asian Platforms: A Regional Survey (The Emerging Platform Economy Series No. 3). The Center for Global Enterprise (2016)

18. Frank, A.G.: Capitalism and Underdevelopment in Latin America. NYU Press, New York (1967)

19. Gaver, W.W.: Technology affordances. In: Proceedings of the SIGCHI Conference on Human Factors in Computing Systems, pp. 79-84 (1991)

20. Gawer, A.: Bridging differing perspectives on technological platforms: toward an integrative framework. Res. Policy 43(7), 1239-1249 (2014)

21. Gawer, A. (ed.): Platforms, Markets and Innovation. Edward Elgar Publishing, Cheltenham (2009)

22. Ghazawneh, A., Henfridsson, O.: Balancing platform control and external contribution in third-party development: the boundary resources model. Inf. Syst. J. 23(2), 173-192 (2013)

23. Gibson, J.J.: The theory of affordances. In: Shaw, R., Bransford, J. (eds.) Perceiving, Acting, and Knowing, pp. 67-82. Lawrence Erlbaum Associates, New York (1977)

24. Hagiu, A., Wright, J.: Multi-sided platforms. Int. J. Ind. Organ. 43, 162-174 (2015)

25. Heeks, R.: Decent Work and the Digital Gig Economy: A Developing Country Perspective on Employment Impacts and Standards in Online Outsourcing, Crowdwork, etc. (Development Informatics, Working Paper Series) (2017)

26. Jackson, J.: How Facebook Made Mobile Site Faster for Users with Limited Bandwidth (2015). https://www.computerworld.com/article/2960779/social-media/how-facebook-mademobile-site-faster-for-users-with-limited-bandwidth.html. Accessed 29 June 2018

27. Jacobides, M., Cennamo, C., Gawer, A.: Towards a theory of ecosystems. Strateg. Manag. J. 39(8), 2255-2276 (2018)

28. Karippacheril, T.G., Nikayin, F., De Reuver, M., Bouwman, H.: Serving the poor: multisided mobile service platforms, openness, competition, collaboration and the struggle for leadership. Telecommun. Policy 37(1), 24-34 (2013)

29. Khanna, T., Palepu, K.G.: Winning in Emerging Markets: A Road Map for Strategy and Execution. Harvard Business Review Press, Boston (2010)

30. Mandel, M.: Where the Jobs Are: The App Economy (2012). http://www.technet.org/wpcontent/uploads/2012/02/TechNet-App-Economy-Jobs-Study.pdf

31. Nastiti, A.: Drivers' stories reveal how exploitation occurs in Gojek, Grab and Uber (2017). http://theconversation.com/drivers-stories-reveal-how-exploitation-occurs-in-gojek-grab-anduber-82689. Accessed 30 June 2018

32. Nielsen, P.: Digital innovation: a research agenda for information systems research in developing countries. In: Choudrie, J., Islam, M.S., Wahid, F., Bass, J.M., Priyatma, J.E. (eds.) ICT4D 2017. IAICT, vol. 504, pp. 269-279. Springer, Cham (2017). https://doi.org/ 10.1007/978-3-319-59111-7_23

33. Norman, D.A.: Affordance, conventions, and design. Interactions 6(3), 38-43 (1999)

34. Ssekibuule, R., Quinn, J.A., Leyton-Brown, K.: A mobile market for agricultural trade in Uganda. In: Proceedings of the 4th Annual Symposium on Computing for Development, pp. 1-10. ACM, New York (2013) 
35. Swaans, K., Boogaard, B., Bendapudi, R., Taye, H., Hendrickx, S., Klerkx, L.: Operationalizing inclusive innovation: lessons from innovation platforms in livestock value chains in India and Mozambique. Innov. Dev. 4(2), 239-257 (2014)

36. Thornton, P.H., Ocasio, W.: Institutional logics and the historical contingency of power in organizations: executive succession in the higher education publishing industry, 1958-1990. Am. J. Sociol. 105(3), 801-843 (1999)

37. Tiwana, A., Konsynski, B., Bush, A.A.: Platform evolution: coevolution of platform architecture, governance, and environmental dynamics. Inf. Syst. Res. 21(4), 675-687 (2010)

38. Toyama, K.: Technology as amplifier in international development. In: Proceedings of the 2011 iConference, pp. 75-82. ACM, New York (2011)

39. Yoo, Y., Boland, R.J.J., Lyytinen, K., Majchrzak, A.: Organizing for innovation in the digitized world. Organ. Sci. 23(5), 1398-1408 (2012)

40. Yoo, Y., Henfridsson, O., Lyytinen, K.: Research commentary. The new organizing logic of digital innovation: an agenda for information systems research. Inf. Syst. Res. 21(4), 724735 (2010) 